\title{
Liquid chromatography tandem mass spectrometry method for quantification of topiramate in human plasma
}

Thitirat Pamorn, Waraphorn Sisan, Jedsadaporn Prakobkijcharoen, Jureeporn Sri-in, Pinpilai Jutasompakorn Suvimol Niyomnaitham, Somruedee Chatsiricharoenkul, Weerawadee Chandranipapongse*

Department of Pharmacology, Faculty of Medicine Siriraj Hospital, Mahidol University, Bangkok, Thailand

\begin{abstract}
A simple and reproducible liquid chromatography coupled to tandem mass spectrometry (LC-MS/MS) method for determination of topiramate in human plasma was developed and validated. The plasma samples were prepared by liquid-liquid extraction (LLE) method which composed of methyl-t-butyl ether and hexane. Topiramate and amlodipine (internal standard; IS) were separated on Luna HST $2.5 \mu \mathrm{m} \mathrm{C18} \mathrm{(50x3} \mathrm{mm.)} \mathrm{column.}$ The mobile phase consisted of acetonitrile and $10 \mathrm{mM}$ ammonium acetate $(90: 10, \mathrm{v} / \mathrm{v})$ at $\mathrm{pH} 4.0$ was run under isocratic condition at a flow rate of $0.3 \mathrm{ml} / \mathrm{min}$. The total run time was $2.5 \mathrm{~min}$. Mass detection was performed in multiple reaction monitoring (MRM) mode under negative electrospray ionization (ESI). The mass transitions were monitored at $\mathrm{m} / \mathrm{z} 337.93>77.78$ for topiramate and $\mathrm{m} / \mathrm{z} 406.92>295.10$ for IS. The lower limit of quantification (LLOQ) was $10 \mathrm{ng} / \mathrm{mL}$ which demonstrated good sensitivity and specificity. The linearity range of the method was $10-3,000 \mathrm{ng} / \mathrm{mL}$ with the correlation coefficients $(\mathrm{r}) \geq 0.995$. The method was economical since it required only $200 \mu \mathrm{L}$ of sample, $1 \mathrm{~mL}$ of solvent and $2 \mu \mathrm{L}$ of injection volume.
\end{abstract}

Keywords:

LC-MS/MS, Topiramate, Amlodipine, Liquid-liquid extraction, Human plasma

\section{INTRODUCTION}

Topiramate is an antiepileptic drug indicated for monotherapy or adjunctive treatment of epilepsy in both children and adults ${ }^{1-3}$. It is also approved for prophylaxis of migraine headache ${ }^{4}$. Furthermore, topiramate has been evaluated for its effect in various neurological and psychiatric disorders ${ }^{5}$. The chemical formula of topiramate is $\mathrm{C}_{12} \mathrm{H}_{21} \mathrm{NO}_{8} \mathrm{~S}$. It is a sulfamate-substituted monosaccharide that has a molecular weight of $339^{1}$. Although, topiramate's mechanism of action has not been fully elucidated, multiple drug actions have been proposed such as blockade of voltage-dependent sodium channels, antagonism of kainate/AMPA subtype of the glutamate receptors and augmentation of GABA activity ${ }^{1-3}$.

Although, several LC-MS/MS methods for determination of topiramate in human plasma have been reported, there are some analytical limitations such as the need for large volume of plasma samples, timeconsuming and complicated sample preparation method, high injection volumes, low sensitivity and narrow linearity range $(10-2000 \mathrm{ng} / \mathrm{mL})^{6-11}$.

This work describes the development and validation of an LC-MS/MS method for determination of topiramate in human plasma that is simple, less timeconsuming of sample preparation and higher recovery compared to aforementioned methods. This method was fully validated and confirmed within the acceptance criteria according to the guidance of the United States Food and Drug Administration (FDA) and the European Medicines Agency (EMA) ${ }^{12-13}$.

\section{MATERIALS AND METHODS}

\subsection{Chemicals and reagents}

Topiramate (99.6\% purity) and amlodipine besylate (99.8\% purity), an internal standard (IS), were obtained from The United States Pharmacopeial Convention, Inc., USA. Their chemical structures were presented

*Weerawadee Chandranipapongse weerawadee.cha@mahidol.ac.th 


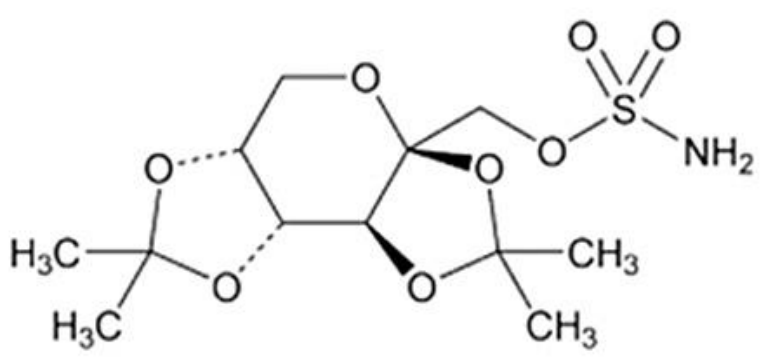

Topiramate<smiles>CCOC(=O)C1=C(COCCN)NC(C)=C(C(=O)OC)C1c1ccccc1Cl</smiles>

Amlodipine besylate
Figure 1. Chemical structures of topiramate and amlodipine besylate.

in Figure 1. Acetonitrile (HPLC grade), Methyl t-butyl ether (AR grade) and Hexane (AR grade) were purchased from Scharlau (Barcelona, Spain). Methanol and Propan-2-ol (HPLC grade) were purchased from Fisher Scientific (Loughborough, United Kingdom). Ammonium acetate ( $\geq 98 \%$ purity) was purchased from Sigma Aldrich Chemie (Gmbh, Germany). Formic acid (AR grade) was purchased from Merck (Darmstadt, Germany). Milli Q water was generated by Type I water purification system (Millipore Corporation, Massachusetts, USA). Blank human plasma with Lithium heparin was obtained from the Department of Transfusion Medicine, Faculty of Medicine Siriraj Hospital, Mahidol University, Bangkok, Thailand.

\subsection{Instruments}

The LC-MS/MS system was the Acquity UPLC system (Waters, Co., Ltd. USA) equipped to the Quattro micro mass spectrometry (Micromass Technologies, UK). The system and data processing were performed by MassLynx software, version 4.1 SCN627. The chromatographic separation of topiramate and amlodipine was carried out at $40^{\circ} \mathrm{C}$ on the Luna HST $2.5 \mu \mathrm{m} \mathrm{C18} \mathrm{(50x3}$ $\mathrm{mm}$.) column from Phenomenex Ltd., USA. The temperature of auto sampler was set at $10^{\circ} \mathrm{C}$ throughout the run. The mobile phase consisted of $10 \mathrm{mM}$ ammonium acetate (adjusted with formic acid to $\mathrm{pH} 4.0$ ) and acetonitrile $(10: 90, \mathrm{v} / \mathrm{v})$ was delivered under the isocratic condition at a flow rate of $0.3 \mathrm{~mL} / \mathrm{min}$. The total run time was $2.5 \mathrm{~min}$. The injection volume was $2 \mu \mathrm{L}$. Mass detection of topiramate and IS was performed using multiple reaction monitoring (MRM) mode under negative electrospray ionization mode. The capillary and cone voltage were set at $3.50 \mathrm{kV}$ and $40 \mathrm{~V}$, respectively. The temperature of ion source was maintained at $120^{\circ} \mathrm{C}$. Desolvation gas flow rate was $550 \mathrm{~L} / \mathrm{h}$ at $350^{\circ} \mathrm{C}$. The optimum collision energy for topiramate and amlodipine were $23 \mathrm{eV}$ and $17 \mathrm{eV}$, respectively.

\subsection{Preparation of stock and working solutions}

Topiramate stock solution used for generating a calibration curve was prepared in methanol to achieve a concentration of $2,835 \mu \mathrm{g} / \mathrm{mL}$. The working solution was obtained by dilution of the stock solution with $50 \%$ methanol to various concentrations ranging from 100$30,000 \mathrm{ng} / \mathrm{mL}$. For the quality control (QC) samples, topiramate stock solution was also prepared in methanol to acquire a concentration of $3,000 \mu \mathrm{g} / \mathrm{mL}$. The working solution was prepared by further dilution of the stock solution with $50 \%$ methanol to acquire concentrations between $100-24,000 \mathrm{ng} / \mathrm{mL}$. The stock solution of IS was dissolved in methanol to reach a concentration of 1,820 $\mu \mathrm{g} / \mathrm{mL}$ and further diluted with $50 \%$ methanol to obtain the concentration of working solution at $30,000 \mathrm{ng} / \mathrm{mL}$. All stock and working solutions were prepared under low light condition and stored in a $-70 \pm 10^{\circ} \mathrm{C}$ freezer until analysis.

\subsection{Preparation of calibration curve and QC samples}

Calibration standard samples were prepared by spiking topiramate working solutions into pooled human blank plasma to obtain the concentration ranging from $10-3,000 \mathrm{ng} / \mathrm{mL}$. The QC samples were prepared in a similar manner. The concentration of QC samples was $10 \mathrm{ng} / \mathrm{mL}$ at LLOQ, $30 \mathrm{ng} / \mathrm{mL}$ at LQC, $1,400 \mathrm{ng} / \mathrm{mL}$ at MQC and 2,400 $\mathrm{ng} / \mathrm{mL}$ at HQC. Every sample was processed under light protection condition.

\subsection{Sample preparation}

Topiramate and IS were isolated from human plasma by liquid-liquid extraction technique under light protection condition. The IS working solution $20 \mu \mathrm{L}$ was added to $200 \mu \mathrm{L}$ of plasma sample. Then $1 \mathrm{~mL}$ of methyl-t-butyl ether and hexane mixture at 19:1 (v/v) was added, vortexed for 10 minutes and centrifuged at $10,000 \mathrm{rpm}, 4^{\circ} \mathrm{C}$ for 10 minutes. The organic layer was then transferred to a $1.5 \mathrm{~mL}$ microcentrifuge tube and dried under nitrogen stream at $30^{\circ} \mathrm{C}$. The residue was reconstituted by adding $200 \mu \mathrm{L}$ mixture of acetonitrile 
and Milli Q water at 1:1 (v/v), then injected into the LCMS/MS system.

\subsection{Method validation}

The developed method was validated according to the FDA and the EMA guidance ${ }^{12-13}$.

\subsubsection{Selectivity}

The selectivity was evaluated by comparing the response of interferences at the retention time of topiramate and IS in an extracted blank plasma sample against that of the QC sample at LLOQ level. Total 14 different sources of blank human plasma with lithium heparin as anticoagulant (10 normal, 2 hemolyzed and 2 lipemic sources) were screened. The minimum six sources of normal blank plasma that showed no interference at the retention time of topiramate and IS were pooled and used for full method validation.

\subsubsection{Carry over effect}

Carry over effect was assessed by injecting a blank sample after the upper limit of quantification (ULOQ) sample. The interfering response in the blank sample following the high concentration standard should be less than $20 \%$ of the LLOQ of topiramate and less than $5 \%$ for the internal standard.

\subsubsection{Linearity}

Three independent calibration curves, each containing 8-point calibration standard, were used to established linearity which ranged from $10-3,000 \mathrm{ng} / \mathrm{mL}$. The LLOQ on a calibration curve required the signal to noise ratio $(\mathrm{S} / \mathrm{N})$ of an analyte to be greater than 5-time of the extracted human blank plasma.

\subsubsection{Accuracy and Precision}

The intra-assay accuracy and precision for topiramate were evaluated in six replicated analyses at four concentration levels of QC sample (LLOQ, LQC, MQC and HQC) in a single batch run. The inter-day accuracy and precision were calculated after repeated analyses in three different batches run on two different days.

\subsubsection{Extraction recovery}

The recovery of topiramate and IS were examined in six replicated analyses at LQC, MQC and HQC levels. The percentage recovery was assessed by comparing the peak area of plasma spiked standards before and after extraction.

\subsubsection{Matrix effect}

Matrix effect was investigated in total 12 different sources including 10 normal, 1 hemolyzed and 1 lipemic blank plasma. Each source replicated four times at LQC and HQC levels. The matrix factors were calculated by comparing the peak area of post-extraction plasma spiked standard to the peak area of non-extraction plasma spiked standard. The IS normalized matrix factors were calculated by dividing the matrix factor of topiramate by that of the IS.

\subsubsection{Dilution integrity}

Dilution integrity was demonstrated by spiking topiramate standard into normal blank plasma to reach the concentration above the ULOQ (1.7 times of $85 \%$ the ULOQ), then frozen it for at least $24 \mathrm{~h}$. Later, it was diluted by human blank plasma to a fraction of $1 / 2,1 / 5$ and $1 / 20$. These fractions covered all the dilutions applied to the study samples and were evaluated by a fresh calibration curve in six replications.

\subsubsection{Hemolysis and Lipemia effect}

To investigate the impact of hemolyzed and lipemic human plasma on the accuracy and precision of the assay, six replications of LLOQ, LQC, MQC and HQC were prepared in hemolyzed and lipemic plasma and analyzed against calibration curve spiked in normal plasma.

\subsubsection{Robustness}

Robustness was evaluated on the same apparatus when changes occurred including different lot but same type of column, different organic solvent lots (reconstituted solvents and mobile phase). Intra-day robustness was assessed by analyzing six replications of quality control samples at LLOQ, LQC, MQC and HQC in a single batch run. Inter-day robustness was performed by analyzing 12 replications of quality control samples at each concentration through two robustness batches run on two consecutive days.

\subsubsection{Reinjection reproducibility}

Reinjection reproducibility was demonstrated by comparing the concentrations of LQC and HQC that were injected at time zero and at 25 hours after autosampler storage at $10 \pm 5^{\circ} \mathrm{C}$. The variation within $\pm 15 \%$ was acceptable.

\subsubsection{Stability}

The stability of stock solutions of topiramate 
and IS were assessed after exposure at room temperature $\left(25 \pm 2^{\circ} \mathrm{C}\right)$ for at least 6 hours and after storage at $-70 \pm$ $10^{\circ} \mathrm{C}$ for 36 days by comparing the peak responses to that of the freshly prepared solution. The difference within $\pm 7 \%$ was acceptable ${ }^{14}$.

The stability of topiramate in plasma were demonstrated by analysis four replications of LQC and HQC under various conditions against those of the freshly prepared QC samples. Freeze and thaw stability was evaluated after processing three cycles of freezing and thawing at $-70 \pm 10^{\circ} \mathrm{C}$ and $25 \pm 2^{\circ} \mathrm{C}$, respectively. For short term stability, the samples were exposed at room temperature $\left(25 \pm 2^{\circ} \mathrm{C}\right)$ for 6 hours. Long term stability was demonstrated after samples storage at $-70 \pm 10^{\circ} \mathrm{C}$ for 36 days. In addition, stability of the processed samples was evaluated by storage the reconstituted sample in an autosampler at $10 \pm 5^{\circ} \mathrm{C}$ for 48 hours and the dried sample at $-70 \pm 10^{\circ} \mathrm{C}$ for 5 days before analysis. The accuracy and difference within $\pm 15 \%$ were acceptable ${ }^{12-14}$.

\section{RESULTS AND DISCUSSION}

\subsection{Method development}

The concentrations of topiramate and internal standard, amlodipine, were analyzed by combined reversed phase liquid chromatography and tandem mass spectrometry (LC-MS/MS). The ion transition was examined on both positive and negative modes. As a result, negative ion mode was selected since it yielded more intense response in multiple reaction monitoring (MRM) transition. The mass spectra of parent and daughter ion were scan at $\mathrm{m} / \mathrm{z} 337.93>77.78$ for topiramate (Figure 2A) and $\mathrm{m} / \mathrm{z}$ 406.92>295.10 for amlodipine, the internal standard (Figure 2B). Other parameters of mass spectrometry were also optimized. Although containing weakly acidic sulfamate group in the structure, topiramate is alkaline $(\mathrm{pKa} 8.7)^{2}$. In order to maximize topiramate peak shape and its ionization efficiency, a low viscosity compound, acetonitrile, and a volatile salt, ammonium acetate were chosen as the mobile phase and $\mathrm{pH}$ of the mobile phase was adjusted to below the pKa value of topiramate. The optimum chromatographic separation of topiramate and internal standard were investigated by varying $\mathrm{pH}$ of mobile phase from 4.0-8.0 and trialing different kinds of column including Luna HST $2.5 \mu \mathrm{m} \mathrm{C18}(50 \times 3 \mu \mathrm{mm}$.) and Kinetex $1.7 \mu \mathrm{m} \mathrm{C18}(50 \mathrm{x} 2.1 \mathrm{~mm}$.). The mobile phase containing acetonitrile and $10 \mathrm{mM}$ ammonium acetate $(90: 10, v / v)$ at $\mathrm{pH} 4.0$ run on the Luna HST $2.5 \mu \mathrm{m} \mathrm{C18}$ $(50 \times 3 \mathrm{~mm}$.) under isocratic elution at a flow rate of 0.3 $\mathrm{ml} / \mathrm{min}$ was considered the most sufficient separation

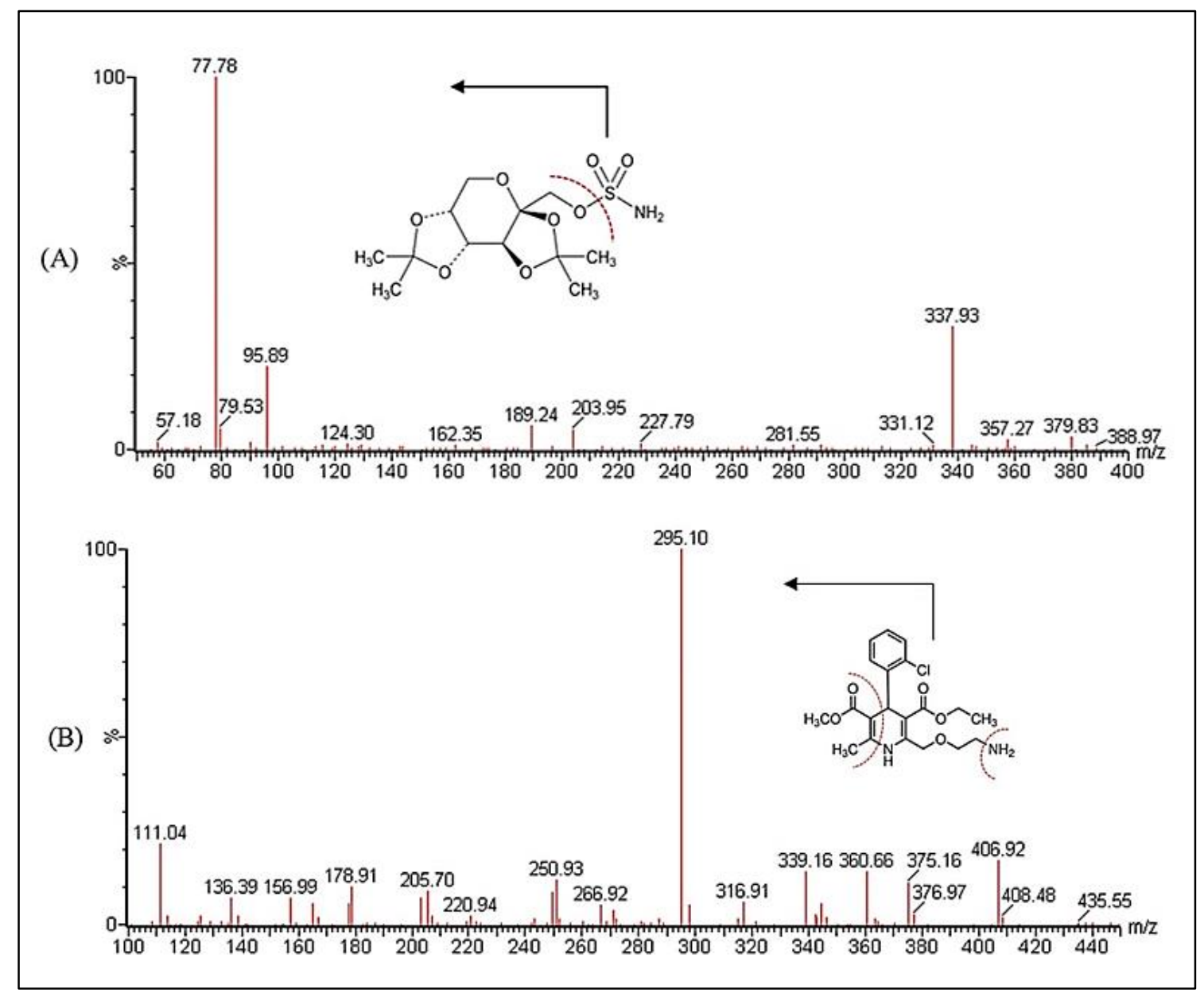

Figure 2. Product ion MS/MS spectra of topiramate (A) and amlodipine (B). 

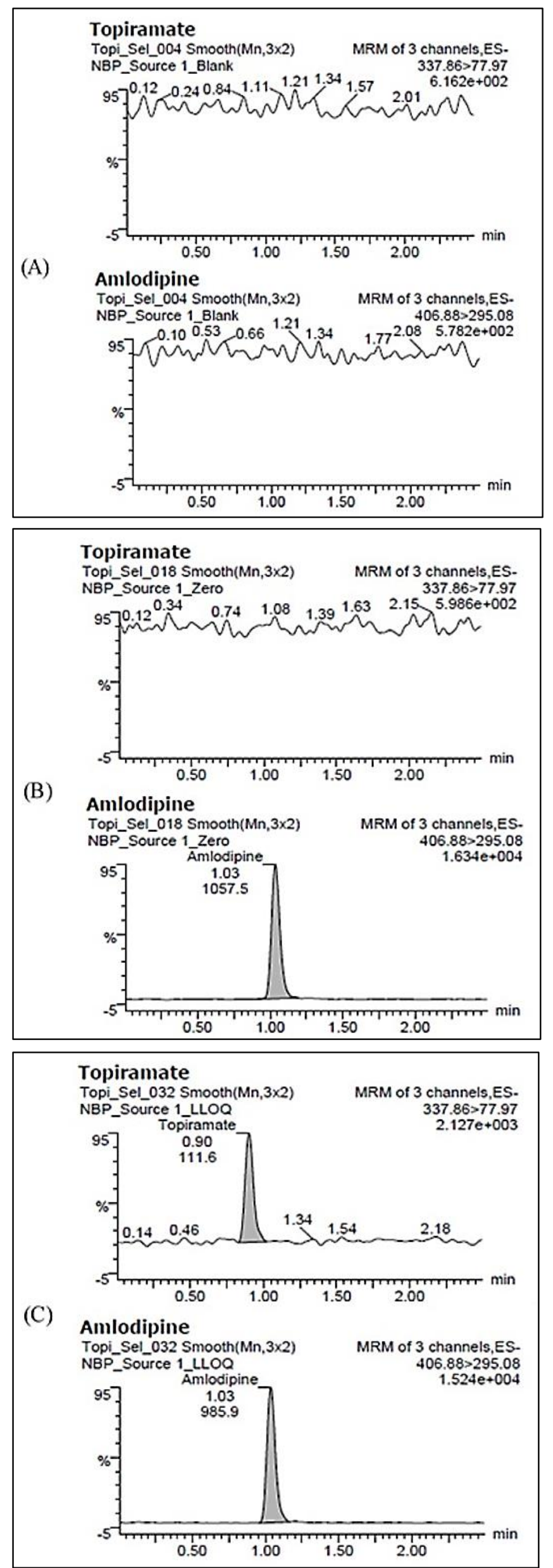

Figure 3. Chromatograms of topiramate and IS in human plasma with lithium heparin as an anticoagulant, Normal blank plasma (A), Normal blank plasma with IS (B), and topiramate LLOQ sample at $10 \mathrm{ng} / \mathrm{mL}(\mathrm{C})$.

because it resulted in symmetric peak shapes with short retention time. For liquid-liquid extraction, methyl-tbutyl ether, ethyl acetate and hexane were trialed either alone or in combination. A mixture of methyl-t-butyl ether and hexane at 19:1 (v/v) produced the highest recovery. The developed method was straightforward and utilized less solvent compared to other reports ${ }^{7,8,10,11}$.

\subsection{Assay performance and validation}

\subsubsection{Selectivity}

Selectivity was demonstrated in human blank plasma. The retention time of topiramate and the IS were 0.90 and $1.03 \mathrm{~min}$, respectively. The area observed at the retention time was less than $20 \%$ of the LLOQ for topiramate and $5 \%$ for the IS. The chromatograms obtained from extracted blank plasma (Figure 3A) and plasma spiked with the IS (Figure 3B) indicated no interfering peaks from endogenous component at the retention time of both topiramate and IS. Figure 3C showed chromatogram of quality control sample at LLOQ concentration $(10 \mathrm{ng} / \mathrm{mL})$. The proposed method exhibited good specificity and efficient extraction for topiramate and the IS.

\subsubsection{Carryover effect}

The injection of blank samples following the ULOQ sample $(3,000 \mathrm{ng} / \mathrm{mL})$ showed no significant interference.

\subsubsection{Linearity and sensitivity}

The limit of detection (LOD) for topiramate was $2 \mathrm{ng} / \mathrm{mL}$. Method sensitivity was evaluated at LLOQ concentration $(10 \mathrm{ng} / \mathrm{mL})$ with a signal to noise ratio of greater than 5 . The percentage of accuracy and precision were $103.33 \%$ and $7.10 \%$, respectively. The lower LLOQ concentration compared to previously reported methods ${ }^{9,15-17}$ indicated good sensitivity.

The calibration curve was established from eight concentration points ranging between 10 to 3,000 $\mathrm{ng} / \mathrm{mL}$ by plotting the peak area ratio of topiramate to the IS against the nominal concentration of topiramate. The simple linear equation was obtained by $1 / \mathrm{x}^{2}$ weighting factor. The correlation coefficient $(\mathrm{r})$ was $\geq 0.995$ which indicated good strength of linear relationship and was shown in Figure 4. The mean back-calculated concentration of three calibration curves was well within the acceptance criteria for accuracy and precision and was presented in Table 1. 


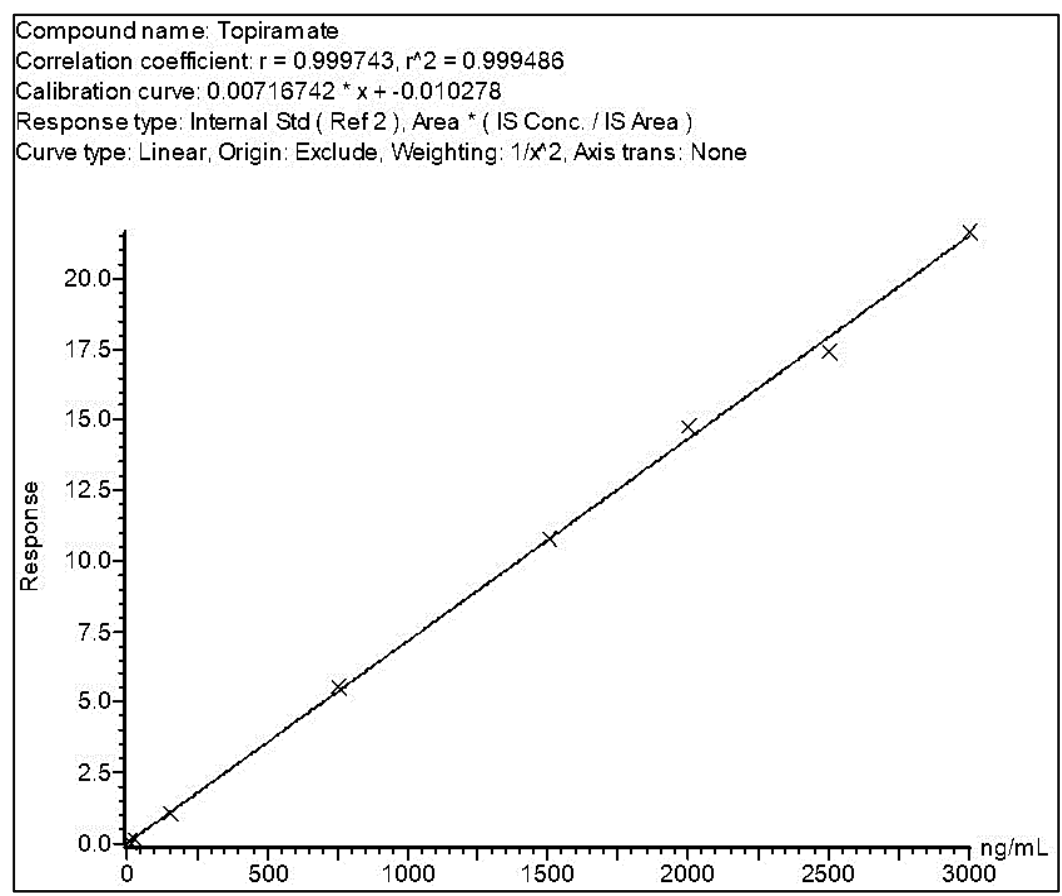

Figure 4. Topiramate calibration curve.

Table 1. Accuracy and Precision of back calculated concentration data from three calibration standards curves.

\begin{tabular}{|c|c|c|c|c|c|c|c|c|}
\hline $\begin{array}{l}\text { Nominal } \\
\text { concentration } \\
\text { (ng/mL) }\end{array}$ & $\begin{array}{c}\text { CS1 } \\
10 \\
\end{array}$ & $\begin{array}{c}\text { CS2 } \\
25 \\
\end{array}$ & $\begin{array}{l}\text { CS3 } \\
150 \\
\end{array}$ & $\begin{array}{l}\text { CS4 } \\
750 \\
\end{array}$ & $\begin{array}{c}\text { CS5 } \\
1500 \\
\end{array}$ & $\begin{array}{l}\text { CS6 } \\
2000 \\
\end{array}$ & $\begin{array}{l}\text { CS7 } \\
2500 \\
\end{array}$ & $\begin{array}{l}\text { CS8 } \\
3000 \\
\end{array}$ \\
\hline Linearity 1 & 10.13 & 24.71 & 146.67 & 770.79 & 1504.06 & 2053.73 & 2427.24 & 3022.07 \\
\hline Linearity 2 & 10.15 & 24.84 & 137.18 & 774.30 & 1471.32 & 2014.40 & 2571.21 & 3128.14 \\
\hline Linearity 3 & 10.37 & 23.31 & 142.17 & 764.36 & 1498.70 & 2089.10 & 2543.39 & 3050.98 \\
\hline Mean & 10.22 & 24.28 & 142.00 & 769.82 & 1491.36 & 2052.41 & 2513.95 & 3067.06 \\
\hline $\mathrm{SD}( \pm)$ & 0.14 & 0.85 & 4.75 & 5.04 & 17.56 & 37.37 & 76.37 & 54.83 \\
\hline $\mathrm{CV}(\%)$ & 1.33 & 3.49 & 3.34 & 0.65 & 1.18 & 1.82 & 3.04 & 1.79 \\
\hline Accuracy $(\%)$ & 101.57 & 96.87 & 94.58 & 102.54 & 99.33 & 102.52 & 100.46 & 102.14 \\
\hline
\end{tabular}

Table 2. Topiramate intra-day (within-run) and inter-day (between-run) accuracy and precision.

\begin{tabular}{|c|c|c|c|c|}
\hline $\begin{array}{l}\text { Nominal concentration } \\
(\mathrm{ng} / \mathrm{mL})\end{array}$ & $\begin{array}{c}\text { LLOQ } \\
10\end{array}$ & $\begin{array}{c}\text { LQC } \\
30\end{array}$ & $\begin{array}{c}\text { MQC } \\
1400\end{array}$ & $\begin{array}{l}\text { HQC } \\
2400\end{array}$ \\
\hline \multicolumn{5}{|l|}{ Within-run 1} \\
\hline Mean $(n=6)$ & 9.71 & 30.10 & 1467.03 & 2458.56 \\
\hline $\mathrm{SD}( \pm)$ & 1.00 & 1.09 & 28.32 & 63.67 \\
\hline $\mathrm{CV}(\%)$ & 10.34 & 3.63 & 1.93 & 2.59 \\
\hline Accuracy (\%) & 96.23 & 100.02 & 104.65 & 102.30 \\
\hline \multicolumn{5}{|l|}{ Within-run 2} \\
\hline Mean $(n=6)$ & 10.53 & 30.65 & 1422.87 & 2398.67 \\
\hline $\mathrm{SD}( \pm)$ & 0.89 & 0.82 & 34.90 & 77.56 \\
\hline $\mathrm{CV}(\%)$ & 8.46 & 2.69 & 2.45 & 3.23 \\
\hline Accuracy (\%) & 104.40 & 101.87 & 101.50 & 99.81 \\
\hline \multicolumn{5}{|l|}{ Within-run 3} \\
\hline Mean $(n=6)$ & 10.43 & 30.50 & 1404.25 & 2454.12 \\
\hline $\mathrm{SD}( \pm)$ & 0.74 & 0.99 & 8.92 & 28.98 \\
\hline $\mathrm{CV}(\%)$ & 7.10 & 3.26 & 0.64 & 1.18 \\
\hline Accuracy $(\%)$ & 103.33 & 101.36 & 100.17 & 102.12 \\
\hline \multicolumn{5}{|l|}{ Between run } \\
\hline Mean $(n=18)$ & 10.22 & 30.42 & 1431.38 & 2437.12 \\
\hline $\operatorname{SD}( \pm)$ & 0.91 & 0.95 & 36.76 & 63.20 \\
\hline $\mathrm{CV}(\%)$ & 8.93 & 3.12 & 2.57 & 2.59 \\
\hline Accuracy (\%) & 101.32 & 101.09 & 102.10 & 101.41 \\
\hline
\end{tabular}


Table 3. Matrix effect of topiramate in twelve different sources of human plasma.

\begin{tabular}{lcccc}
\hline \multirow{2}{*}{ Sources } & \multicolumn{2}{c}{ MF of topiramate } & \multicolumn{2}{c}{ IS normalized MF } \\
\cline { 2 - 5 } & LQC & HQC & LQC & HQC \\
\hline No. 1 & 0.98 & 0.99 & 1.03 & 1.04 \\
No. 2 & 0.93 & 0.93 & 0.97 & 0.97 \\
No. 3 & 0.93 & 0.96 & 0.97 & 1.00 \\
No. 4 & 0.98 & 0.92 & 0.99 & 0.93 \\
No. 5 & 0.98 & 1.03 & 0.95 & 1.00 \\
No. 6 & 0.91 & 0.99 & 0.93 & 1.01 \\
No. 7 & 0.94 & 0.95 & 0.98 & 0.99 \\
No. 8 & 0.97 & 0.99 & 0.99 & 1.01 \\
No. 9 & 0.93 & 0.93 & 0.99 & 0.99 \\
No. 10 & 0.97 & 1.00 & 1.00 & 1.03 \\
No. 11 (Hemolysis) & 0.93 & 0.95 & 0.97 & 0.99 \\
No. 12 (Lipemia) & 1.05 & 1.04 & 1.06 & 1.05 \\
\hline Mean & 0.96 & 0.97 & 0.99 & 1.00 \\
SD $( \pm)$ & 0.04 & 0.04 & 0.03 & 0.03 \\
CV $(\%)$ & 4.17 & 4.12 & 3.03 & 3.00 \\
\hline
\end{tabular}

\subsubsection{Accuracy and Precision}

The intra-day and inter-day accuracy and precision were evaluated by analysis of six replicates of LLOQ, LQC, MQC and HQC samples. The data of accuracy and precision were summarized in Table 2. The percentage of accuracy and precision was well within $\pm 20 \%$ at LLOQ level and within $\pm 15 \%$ at other concentrations. The results revealed that this method was accurate, precise and reproducible for analysis.

\subsubsection{Extraction recovery}

The extraction recovery of topiramate at LQC, MQC and HQC levels were 83.28\%, 83.07\% and 82.92\%, respectively whereas the overall average recovery of IS was $74.09 \%$. The results indicated sufficient and reproducible liquid-liquid extraction technique for topiramate and IS. Although the solid phase extraction in other studies yielded better recovery $(93.22-105.5 \%)^{10,11}$, the liquid-liquid extraction was continued because it produced acceptable recovery. Moreover, the liquidliquid extraction for large number of samples was more affordable when compared to the solid phase extraction.

\subsubsection{Matrix effect}

The matrix factor (MF) of topiramate calculated at LQC and HQC level ranged from 0.91-1.05 with the $\mathrm{CV}$ of $4.12-4.17 \%$ and the IS normalized MF ranged from $0.93-1.06$ with the CV of 3.00-3.03\% (Table 3). The matrix factor of IS was 0.97 with the CV of $2.49 \%$. The matrix factors of topiramate, IS and IS normalized MF within 0.85-1.15 indicated neither ion suppression nor ion enhancement from endogenous substances in plasma sample.
The dilution integrity covered the dilution to a fraction of $1 / 2(2,550 \mathrm{ng} / \mathrm{mL}), 1 / 5(1,020 \mathrm{ng} / \mathrm{mL})$ and $1 / 20$ $(255 \mathrm{ng} / \mathrm{mL})$. The accuracy of the dilution integrity was 99.34, 97.54 and $93.37 \%$ and the precision was $2.49,1.69$ and $1.73 \%$, respectively. Accuracy and precision were well within $\pm 15 \%$ of the acceptance criteria.

\subsubsection{Hemolysis and Lipemia effect}

The accuracy and precision of hemolysis and lipemia effects were summarized in Table 4. The accuracy varied within $20 \%$ of nominal concentration at LLOQ and within $15 \%$ at other concentrations. The precision (\%CV) at LLOQ level was not exceed $20 \%$ and was within $15 \%$ at other concentrations. The results indicated no significant hemolysis and lipemia effects on accuracy and precision of this method.

\subsubsection{Robustness}

Intra- and inter-day accuracy were $97.29-105.02 \%$ and $100.77-102.66 \%$, respectively. Intra- and inter-day precision were $1.45-9.04 \%$ and $3.21-7.67 \%$, respectively. These results ensured the robustness of this method.

\subsubsection{Reinjection reproducibility}

Reinjection reproducibility was performed to ensure a sample re-analysis when an unexpected event had interrupted the analysis. The percentage variation of the reinjected samples was $5.67 \%$ and $2.55 \%$ at LQC and $\mathrm{HQC}$ concentration, respectively after autosampler storage for 25 hours. The results suggested that the samples were consistent within 25 hours.

\subsubsection{Stability}

The stock solution of topiramate and IS were

\subsubsection{Dilution integrity}


stable at room temperature $\left(25 \pm 2^{\circ} \mathrm{C}\right)$ for 11 hours and at $-70 \pm 10^{\circ} \mathrm{C}$ for 36 days.

Stability studies were performed under various conditions and summarized in Table 5. Topiramate in human plasma was stable at $25 \pm 2^{\circ} \mathrm{C}$ for 6 hours, at $-70 \pm$ $10^{\circ} \mathrm{C}$ for 36 days and after three cycles of freeze and thaw. In addition, the reconstituted topiramate samples were unaffected when kept in an autosampler at $10 \pm 5^{\circ} \mathrm{C}$ for 48 hours. Similarly, the dry extracted of topiramate samples were not altered after freezing at $-70 \pm 10^{\circ} \mathrm{C}$ for 5 days. These results indicated the stability of topiramate in human plasma under storage or operating conditions.

\section{CONCLUSIONS}

In this study, the LC-MS/MS method for quantification of topiramate in human plasma has been successfully developed and validated according to the USFDA and EMA guidelines. This method employed uncomplicated LLE technique that demonstrated acceptable sensitivity and specificity at reasonable cost. Furthermore, the method allowed small quantity of sample $(200 \mu \mathrm{L})$, small volume of solvent $(1 \mathrm{~mL})$ and only needed $2-\mu \mathrm{L}$ injection volume. A run time of 2.5 minutes per sample permitted an analysis of over 500 samples per day.

Table 4. Effect of hemolysis and lipemia on accuracy and precision.

\begin{tabular}{|c|c|c|c|c|}
\hline $\begin{array}{l}\text { Nominal concentration } \\
(\mathrm{ng} / \mathrm{mL})\end{array}$ & $\begin{array}{c}\text { LLOQ } \\
10 \\
\end{array}$ & $\begin{array}{c}\text { LQC } \\
\mathbf{3 0} \\
\end{array}$ & $\begin{array}{c}\text { MQC } \\
1400 \\
\end{array}$ & $\begin{aligned} \text { HQC } \\
2400 \\
\end{aligned}$ \\
\hline \multicolumn{5}{|l|}{ Effect of hemolysis } \\
\hline Mean $(n=6)$ & 10.61 & 30.51 & 1519.85 & 2484.29 \\
\hline $\mathrm{SD}( \pm)$ & 0.58 & 1.28 & 21.90 & 59.67 \\
\hline $\mathrm{CV}(\%)$ & 5.46 & 4.19 & 1.44 & 2.40 \\
\hline Accuracy (\%) & 105.19 & 101.41 & 108.41 & 103.37 \\
\hline \multicolumn{5}{|l|}{ Effect of lipemia } \\
\hline Mean $(n=6)$ & 10.74 & 30.95 & 1503.15 & 2464.95 \\
\hline $\mathrm{SD}( \pm)$ & 0.55 & 1.98 & 46.33 & 47.52 \\
\hline $\mathrm{CV}(\%)$ & 5.09 & 6.41 & 3.08 & 1.93 \\
\hline Accuracy (\%) & 106.45 & 102.85 & 107.22 & 102.57 \\
\hline
\end{tabular}

Table 5. Topiramate stability data in human plasma under various conditions.

\begin{tabular}{|c|c|c|c|c|c|}
\hline Stability test & QC samples & $\operatorname{Mean} \pm \operatorname{SD}(\mathrm{ng} / \mathrm{mL})$ & $\mathrm{CV}(\%)$ & Accuracy (\%) & Difference (\%) \\
\hline \multirow{2}{*}{$\begin{array}{l}\text { Freeze and thaw stability } \\
\text { at }-70 \pm 10{ }^{\circ} \mathrm{C} \text { for } 3 \text { cycles }\end{array}$} & LQC (30 ng/mL) & $27.10 \pm 0.51$ & 1.87 & 90.08 & 9.27 \\
\hline & HQC $(2400 \mathrm{ng} / \mathrm{mL})$ & $2229.90 \pm 28.97$ & 1.30 & 92.79 & 8.60 \\
\hline \multirow{2}{*}{$\begin{array}{l}\text { Short term stability } \\
\text { at } 25 \pm 2^{\circ} \mathrm{C} \text { for } 6 \mathrm{~h}\end{array}$} & LQC (30 ng/mL) & $30.72 \pm 1.78$ & 5.80 & 102.11 & 2.85 \\
\hline & HQC $(2400 \mathrm{ng} / \mathrm{mL})$ & $2535.42 \pm 59.62$ & 2.35 & 105.50 & 3.93 \\
\hline \multirow{2}{*}{$\begin{array}{l}\text { Long term stability } \\
\text { at }-70 \pm 10{ }^{\circ} \mathrm{C} \text { for } 36 \text { days }\end{array}$} & LQC (30 ng/mL) & $28.15 \pm 1.49$ & 5.29 & 93.57 & 5.42 \\
\hline & HQC $(2400 \mathrm{ng} / \mathrm{mL})$ & $2519.59 \pm 33.59$ & 1.33 & 104.84 & 3.51 \\
\hline \multirow{2}{*}{$\begin{array}{l}\text { Post-preparative stability } \\
\text { at } 10 \pm 5^{\circ} \mathrm{C} \text { for } 48 \mathrm{~h}\end{array}$} & LQC (30 ng/mL) & $30.00 \pm 1.16$ & 3.88 & 99.71 & 0.44 \\
\hline & HQC $(2400 \mathrm{ng} / \mathrm{mL})$ & $2612.24 \pm 112.01$ & 4.29 & 108.69 & 7.08 \\
\hline \multirow{2}{*}{$\begin{array}{l}\text { Post-preparative stability } \\
\text { at }-70 \pm 10{ }^{\circ} \mathrm{C} \text { for } 5 \text { days }\end{array}$} & LQC (30 ng/mL) & $28.82 \pm 2.09$ & 7.24 & 95.79 & 3.51 \\
\hline & HQC $(2400 \mathrm{ng} / \mathrm{mL})$ & $2400.54 \pm 42.31$ & 1.76 & 99.89 & 1.60 \\
\hline
\end{tabular}

\section{ACKNOWLEDGEMENT}

The authors gratefully thank Department of Transfusion Medicine, Faculty of Medicine Siriraj Hospital, Mahidol University, Bangkok, Thailand for the support of drug-free human plasma.

\section{Conflict of interest}

All authors declare no conflicts of interest in preparing this article.

\section{Funding}

PJ, SN, SC and WC were supported by a Chalermprakiat Grant, Faculty of Medicine Siriraj Hospital, Mahidol University, Bangkok, Thailand.

\section{Ethical approval}

The Institutional Review Board of Faculty of Medicine Siriraj Hospital, Mahidol University, Bangkok, Thailand approved the study protocol. (COA no. Si167/2017)

\section{Article info:}

Received March 9, 2021

Received in revised form April 28, 2021

Accepted June 18, 2021

\section{REFERENCES}

1. Sachdeo RC. Topiramate. Clinical profile in epilepsy. Clin pharmacokinet. 1998;34(5):335-46.

2. Shank RP, Gardocki JF, Streeter AJ, Maryanoff BE. An overview of the preclinical aspects of topiramate: pharmacology, pharmacokinetics, and mechanism of action. Epilepsia. 2000; 41(S1):3-9. 
3. McCabe PH, Eslinger PJ. Abnormal Wada and neuropsychological testing results due to topiramate therapy. Epilepsia. 2000; 41(7):906-8.

4. Shank RP, Maryanoff BE. Molecular pharmacodynamics, clinical therapeutics, and pharmacokinetics of topiramate. CNS Neurosci Ther. 2008;14(2):120-42.

5. Arnone D. Review of the use of Topiramate for treatment of psychiatric disorders. Ann Gen Psychiatry. 2005;4(1):5.

6. Park JH, Park YS, Lee MH, Rhim SY, Song JC, Lee SJ, et al. Determination of plasma topiramate concentration using LCMS/MS for pharmacokinetic and bioequivalence studies in healthy Korean volunteers. Biomed chromatogr. 2008;22(8):822-9.

7. Goswami D, Kumar A, Khuroo AH, Monif T, Rab S. Bioanalytical LC-MS/MS method validation for plasma determination of topiramate in healthy Indian volunteers. Biomed chromatogr. 2009;23(11):1227-41.

8. Kuchekar SR, Kundlik ML, Zaware BH. Rapid and Specific Approach for Direct Measurement of Topiramate in Human Plasma by LC-MS/MS: Application for Bioequivalence Study. J Bioanal Biomed. 2010;02(5):107-12.

9. Matar KM. Therapeutic drug monitoring of topiramate by liquid chromatography-tandem mass spectrometry. Clin Chim Acta. 2010;411(9-10):729-34

10. Popov TV, Maricic LC, Prosen H, Voncina DB. Determination of topiramate in human plasma using liquid chromatography tandem mass spectrometry. Acta Chimica Slovenica. 2013; 60(1):144-50.
11. Das GK. Estimation of Topiramate in human plasma using LCMS/MS method. Asian J Pharma Clin Res. 2013;6:217-20.

12. U.S. Department of Health and Human Services Food and Drug Administration Center for Drug Evaluation and Research (CDER). Guidance for Industry Bioanalytical method validation. 2018.

13. European Medicines Agency, Committee for Medicinal Products for Human Use. Guideline on bioanalytical method validation. 2011.

14. Nowatzke W, Woolf E. Best practices during bioanalytical method validation for the characterization of assay reagents and the evaluation of analyte stability in assay standards, quality controls, and study samples. AAPS J. 2007;9(2):E117-22.

15. Chen S, Carvey PM. Rapid approach to the quantitative determination of topiramate (2, 3:4,5-bis-O-(1-methylethylidene)beta-D-fructopyranose sulfamate) in human plasma by liquidliquid extraction and flow-injection negative-ion electrospray mass spectrometry. Rapid Commun Mass Spectrom. 1999;13 (20):1980-4.

16. Chen S, Carvey PM. Validation of liquid-liquid extraction followed by flow-injection negative ion electrospray mass spectrometry assay to Topiramate in human plasma. Rapid Commun Mass Spectrom. 2001;15(2):159-63.

17. Thummar K, Jethva D, Sheth N. Quantitative analysis of topiramate in human plasma using LC-MS/MS and its application to pharmacokinetic study. World J Pharm Pharm Sci. 2018;7(5): 1016-32. 